\title{
Biopolíticas da saúde: reflexões a partir de Michel Foucault, Agnes Heller e Hannah Arendt
}
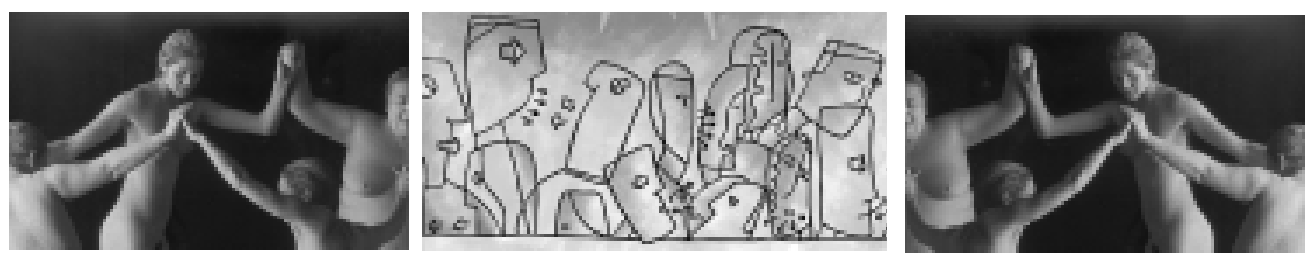

Francisco Ortega ${ }^{1}$

ORTEGA, F. The biopolitics of health: reflections on Michel Foucault, Agnes Heller e Hannah Arendt, Interface Comunic., Saúde, Educ., v.8, n.14, p.9-20, set.2003-fev.2004.

The purpose of this article is to offer conceptual tools that may help one to reflect on the biopolitics of health, based on the works of Michel Foucault, Agnes Heller and Hannah Arendt. For Foucault, since the $18^{\text {th }}$ century, biological life and the health of the nation became fundamental targets of a power over life that emphasized the notions of sexuality, race and degeneration in particular, with the objective of optimizing the biological quality of the population. For Arendt, this trend toward the politicization of life is deeply antipolitical. Life fills the void left by the decomposition of the public sphere. In the case of Agnes Heller, the antipolitical character of the biopolitical discourse manifests itself in the ongoing quest for near-scientific legitimization. The thoughts on race, gender and health mimic scientific thinking and replace opinion by truth. If politics is the arena for the confrontation of opinions, dialogue, initiative, novelty, spontaneity and free action, scientifically legitimated biopolitical thinking is the space of truth, certainty, necessity, determinism and causality, where dialogue is substituted by the politics of self-seclusion, of friends and enemies, and the plurality of opinions is reduced to a single politically correct opinion.

KEY WORDS: Biopolitics; health; Michel Foucault; Agnes Heller; Hannah Arendt.

O objetivo deste artigo é oferecer ferramentas conceituais que possam ajudar na reflexão acerca da questão das biopolíticas da saúde a partir da obra de Michel Foucault, Agnes Heller e Hannah Arendt. Para Foucault, desde o século XVIII, a vida biológica e a saúde da nação tornaram-se alvos fundamentais de um poder sobre a vida que enfatizava especialmente as noções de sexualidade, raça e degenerescência, cujo objetivo era a otimização da qualidade biológica das populações. Para Arendt, esse movimento de politização da vida é profundamente antipolítico. A vida passa a ocupar o vazio deixado pela decomposição do âmbito público. No caso de Agnes Heller, o antipolitismo do discurso biopolítico se manifesta na procura constante de legitimação quase científica. $O$ pensamento de raça, gênero, saúde é um pensamento científico imitado que substitui a opinião pela verdade. Se a política é o campo do confronto das opiniões, do diálogo, da iniciativa, do novo, da espontaneidade e da ação em liberdade, o pensamento biopolítico legitimado cientificamente é o espaço da verdade, da certeza, da necessidade, do determinismo e da causalidade, no qual o diálogo é substituído por uma política da autoclausura, de amigos e inimigos, e a pluralidade de opiniões é reduzida a uma única opinião politicamente correta.

PALAVRAS CHAVE: Biopolítica; saúde; Michel Foucault; Agnes Heller; Hannah Arendt.

\footnotetext{
${ }_{1}^{1}$ Professor do Instituto de Medicina Social da Universidade do Estado do Rio de Janeiro; Pesquisador do Programa de Estudos e Pesquisas do Sujeito e da Ação (PEPAS/ UERJ). <fjortega@superig.com.br>
} 
No fim do século $x X$, entretanto, toda teoria crítica deve se ocupar seriamente da penetração da bioidentidade no âmbito do político, seja só para analisar as razões desse desenvolvimento e seus efeitos (Heller, 1995)

Segundo Michel Foucault, nossa sociedade atravessou o "umbral da modernidade biológica" na passagem do século XVIII para o XIX, quando o indivíduo e a espécie entraram nas estratégias e nos cálculos do poder político. A vida biológica e a saúde da nação tornaram-se alvos fundamentais de um poder sobre a vida, num processo denominado de "estatização do biológico". O biopoder clássico articulava-se numa dupla forma, como uma anátomo-política do corpo, em cuja base estavam os processos de disciplinamento corporal, e como uma biopolítica das populações. A biopolítica analisada por Foucault enfatizava especialmente as noções de sexualidade, raça e degenerescência, cujo objetivo era a otimização da qualidade biológica das populações. Ela estava historicamente vinculada à constituição e ao fortalecimento do Estado nacional, à afirmação da burguesia, assim como à formação de um dispositivo médico-jurídico visando à medicalização e à normalização da sociedade (Foucault, 1976, 1999a, 1999b).

Em análises clássicas, Hannah Arendt $(1995,1997)$ também diagnosticou o "umbral da modernidade biológica", quando, nas suas investigações sobre o fenômeno totalitário, sublinhava como nos campos de concentração nazistas e stalinistas operava-se a transformação da natureza humana, visando a redução biopolítica dos indivíduos ao mero fato biológico, à "vida nua", ou ao que ela chamava a "abstrata nudez de ser unicamente humano". Essas análises têm sua continuidade na crítica arendtiana da modernidade, segundo a qual a condição vital destrói as condições mundanas e plurais da existência. Se no totalitarismo o poder artificialista da técnica era utilizado para reduzir a humanidade ao fato biológico, nas sociedades liberais modernas recorre-se à mesma artificialidade com o objetivo de aumentar o poder do processo vital natural, tornado norma implícita da vida em comum. A vida tornou-se uma "verdade axiomática" de validade incontestável; o caráter sagrado da vida e a vitória do "animal laborans" na modernidade está vinculado ao processo de crescente despolitização, em que a vontade de agir transformou-se "na passividade mais mortal e estéril que a história jamais conheceu". O regime biopolítico das sociedades liberais pós-totalitárias se encontra sob o primado da "imortalidade do processo vital", que invadiu o espaço público e tornouse regra de organização social, ligado à negação da instituição do mundo como regra de organização política da pluralidade humana. Com isso, a vida passa a ocupar o vazio deixado pela decomposição do âmbito público. Esse movimento de politização da vida - o que Foucault qualifica de biopoder -, que teve seu início nas sociedades ocidentais no século XVIII, é para Arendt profundamente antipolítico. 
2 Encontramos em Deleuze (1986, p.98) uma formulação semelhante: " $A$ vida torna-se resistência ao poder quando o poder assume como objeto a vida. Neste caso também as duas operações pertencem a um mesmo horizonte".

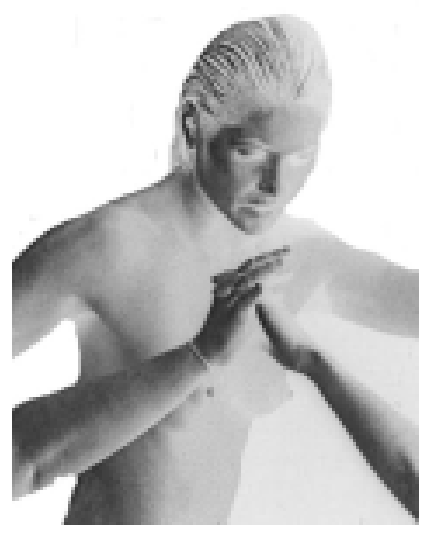

Arendt e Foucault alertaram para as conseqüencias desse processo de tornar a vida o bem supremo, de politização do biológico, sendo o totalitarismo, ou a intimização e a normalização da sociedade, as suas manifestações fundamentais. Dessa maneira, vemos como a biopolítica estatal clássica estava diretamente vinculada à formação $e$ à consolidação da sociedade íntima. Especialmente a ênfase dada à sexualidade na biopolítca era ligada a um processo de implantação de identidades via o desejo sexual. A moral do desejo teria levado desde o cristianismo até a psicanálise à constituição de uma noção de subjetividade passiva e a-histórica, como interioridade e consciência de si, que se encontra na base da filosofia do sujeito. O desejo está ligado à produção de corpos dóceis, submissos e disciplinados, à consistência ontológica da subjetividade e ao universalismo ético que possibilitava a implantação de uma identidade nas práticas subjetivantes modernas.

Para Foucault (1976) a resistência ao dispositivo biopolítico se encontra na vida mesma, numa "outra economia do corpo e dos prazeres", num 'poder da vida', suscetível de resistir os agenciamentos do 'poder sobre a vida' que define a biopolítica. Ele acreditava que a resistência a essa nova forma de poder devia se apoiar precisamente naquilo que ele investiu, isto é, na vida mesma: " $A$ vida como objeto político foi de certa maneira tomada ao pé da letra e voltada contra o sistema que pretendia controlá-la" $(p .191)^{2}$. A vida constitui, portanto, o alvo de lutas biopolíticas, mesmo sob a forma de lutas por um direito à vida, à saúde, ao corpo, à higiene, à felicidade e à satisfação das necessidades. A resistência se organiza como formação de diversos grupos biopolíticos, os quais representam o alvo da crítica de Agnes Heller, como veremos. A posição de Foucault é, no entanto, ambígua: tratar-se-ia de resistir "na biopolítica" ou “à biopolítica"?, pois existem na sua obra momentos em que aparentemente não existiria um "fora" da biopolítica, - a mencionada localização no corpo e nos prazeres como alternativa ao dispositivo biopolítico parecem nos conduzir nessa direção. Por outra parte, nos seus últimos textos, particularmente nos referentes a uma politização da amizade, Foucault se afastou dessa concepção de um poder sobre a vida que biopoliticamente enfrentasse os dispositivos biopolíticos estatais (Ortega, 1999, 2000, 2002). O autor teria se recusado a procurar a resistência no âmbito das identidades e constantes biológicas. Uma leitura de Foucault com um olhar arendtiano pode ser, nesse sentido, frutífera.

A reflexão de Agnes Heller sobre a biopolítica tem como pano de fundo às análises arendtianas e foucaultianas, com as quais estabelece uma fecunda discussão. Sua posição, no entanto, contrasta com a desses autores em vários aspectos. Foucault estava interessado em traçar a genealogia da biopolítica clássica, como a forma adotada por um poder que substitui a lei $e$ o direito pela norma, e a morte pela vida, apontando formas de resistência aos processos normalizadores da sociedade. O alvo de Heller o constituem precisamente esses grupos biopolíticos, mostrando como representam - na melhor tradição arendtiana - antes depauperações do político, formas antipolíticas de agrupamento, do que exercícios de uma política genuína, pois os critérios de agrupamento biológicos e corporais (raça, sexo, saúde, 
performances físicas, doenças específicas, longevidade) substituem os critérios políticos de agrupamento.

Heller extrai do arsenal conceitual arendtiano a sua crítica da biopolítica: "Segundo Arendt, os confrontos sobre a raça e, em geral, sobre todo o biológico na natureza (o sexual incluído) são apolíticos por definição. Para ela, um conceito como 'biopolítica' seria uma contradição em si. Ou 'bio' ou 'política', juntos não é possível' (Heller, 1995, s/p). O âmbito do político constituía-se tradicionalmente precisamente mediante a separação do espaço do oikos, ou seja, da vida doméstica e das necessidades biológicas, do espaço público, o que corresponde à distinção aristotélica entre zoe e bios, entre vida biológica e vida politicamente qualificada. Mesmo se o processo da progressiva inclusão da zoe no âmbito do bios, da estatização do biológico, parece irreversível, para Heller, e fiel ao esquema arendtiano, a biopolítica não pode ser considerada política, constituindo antes o resíduo totalitário remanescente nas sociedades democráticas. Com outras palavras, "a política de uma sociedade totalitária que existe junto às instituições políticas livres" (Heller, 1995, s/p).

Numa série de lúcidas análises, Giorgio Agamben (1998, p.20) nos adverte que enquanto não se resolvam as contradições inerentes ao fato de ter erigido a vida como valor único e supremo de nossa política, nazismo $e$ fascismo - exemplos extremos de politização da vida - "continuaram sendo infelizmente atuais". Um diagnóstico que converge com o de Heller E Fehér (1995, p.57-8) no seu livro intitulado Biopolítica:

\footnotetext{
Há algum perigo grave nos movimentos [biopolíticos] que não podem ser acusados de pretender uma tomada totalitária do poder do Estado, mas que utilizam antes os canais 'normais' da democracia liberal de hoje? (...) Aborda-se com demasiada freqüência a democracia e o totalitarismo como opostos excludentes, e identifica-se com inconsistência total o totalitarismo com o Estado totalitário. Em contrapartida, nós acreditamos que os micropoderes da sociedade - se operar neles uma quantia suficiente de frustração social sem canalizar - podem converter a vida num pesadelo totalitário, sem precisar eliminar todo o mecanismo de eleições livres, parlamentos e separação de poderes. E é indubitável que haja frustração coletiva atrás da biopolítica.
}

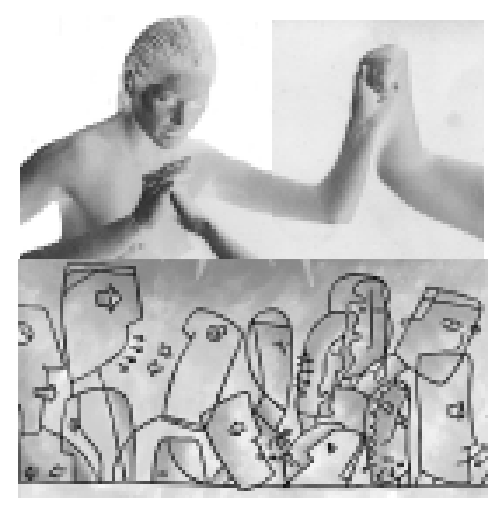

Heller não poupa adjetivos desdenhosos na sua caracterização da biopolítica: "triunfo póstumo de Hitler", "política da autoclausura", "infecção totalitária", "veneno totalitário". Frente ao discurso político baseado na pluralidade de opiniões - no qual precisamente esses dois elementos, pluralidade e opinião, constituem suas características fundamentais -, o discurso biopolítico substitui a pluralidade pela identidade, e a opinião pela verdade e a existência de uma única opinião "politicamente correta". A redução biológica da pluralidade à identidade homogeneíza as diferenças, visando à coesão e à unidade do grupo. Essa homogeneização do grupo qua diferença está para Heller (1995, s/p) "sobrecarregada ideologicamente", 
pois suprime as diferenças dentro do próprio grupo:

\begin{abstract}
Portanto, quem fala em nome da raça caucasiana estabelece uma concordância entre pessoas que não têm nada em comum entre elas, pelo menos nada que considerem importante. Os que falam em nome das mulheres se colocam no lugar de todas as mulheres, da metade da humanidade, enquanto que as mulheres podem ter e de fato têm aspirações totalmente diferentes $e$ imagens de si completamente divergentes; possivelmente recusam a imagem prescrita por feministas radicais. Em vez de uma consciência de classe prescrita temos que lidar aqui com uma consciência de gênero prescrita sem que se reconheça, como Lukács fez.
\end{abstract}

Outro elemento do antipolitismo do discurso biopolítico constitui sua procura constante de legitimação quase científica. Para Heller, o pensamento de raça, gênero, saúde é um "pensamento científico imitado". O pensamento científico substitui a opinião pela verdade. Se a política é o campo do confronto das opiniões, do diálogo, da iniciativa, do novo, da espontaneidade e da ação em liberdade, o pensamento biopolítico legitimado cientificamente é o espaço da verdade, da certeza, da necessidade, do determinismo e da causalidade, no qual o diálogo é substituído por uma política da autoclausura, de amigos e inimigos. ${ }^{3}$ A redução da pluralidade de opiniões a uma única opinião politicamente correta é outro traço antipolítico fundamental dos grupos organizados biopoliticamente:
No discurso biopolítico os grupos autodefinidos determinam também as condições às contribuições dos outros. Um discurso que 'desmascara' outros discursos, que trata com desconfiança o diferente, não é em realidade público. Todas as raças e ambos os sexos encontram aqui sua própria verdade; e quanto mais poderosos são seus lobbys mais enfaticamente tentam proclamar sua verdade como incontestável e absoluta. As opiniões divergentes não são aceitas, $e$ as opiniões contrárias não são ouvidas. (Heller, 1995, s/p)

A biopolítica da saúde é um caso que merece uma atenção especial dentro do espectro biopolítico. As biopolíticas oitocentistas clássicas estudadas por Foucault estavam, como vimos, ao serviço da formação dos Estados nacionais e das classes burguesas - as quais, substituindo uma simbólica do sangue por uma analítica da sexualidade, opunham uma série de novos valores: saúde, higiene, vitalidade, prole, ao sangue e à linhagem aristocrática. Durante o século XX essas questões deixaram de ser objeto de gerenciamento estatal, tornando-se ora problemas privados, ora assuntos sociais. No entanto, pela formação de grupos biopolíticos a saúde está sendo repolitizada biopoliticamente enquanto metáfora de pureza moral. É um projeto de cunho conservador, reação ao culto da promiscuidade das drogas e dos excessos próprios da permissividade dos anos 1960, como podemos observar 
por exemplo na onda de histeria coletiva desencadeada nos EUA pelas campanhas antitabaco. "Como a pureza é um valor moral tão positivo, $e$ ao mesmo tempo tão intolerante", afirmam Heller \& Fehér (1995, p.75-6),

nada que seja oposto a ela pode pretender ocupar uma posição central, a menos que aceite o risco de que lhe seja aplicada a etiqueta de 'perverso' (numa versão suave) ou de diretamente 'diabólico'. Não é nada disparatado ver nessa valorização moral histérica uma tentativa (bio)política de repor a 'saúde' na sua posição central normativa.

A saúde deixou de ser a "vida no silêncio dos órgãos", usando a expressão feliz de Leriche. Ela exige autoconsciência de ser saudável, deve ser exibida, afirmada continuamente e de forma ostentosa, constituindo um princípio fundamental de identidade subjetiva. A Saúde perfeita tornou-se a nova utopia apolítica de nossas sociedades. Ela é tanto meio quanto finalidade de nossas ações. Saúde para a vida. Mas também viver para estar em boa saúde. Viver para fazer viver as biotecnologias. Assim, a nova moral que estrutura a biopolítica da saúde é a
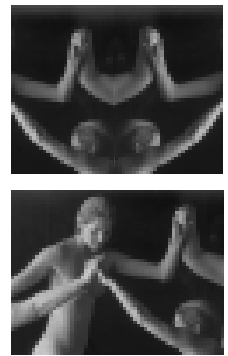

moral do bem-comer (sem colesterol), beber um pouco (vinho tinto para as artérias), ter práticas sexuais de parceiro único (perigo de AIDS), respeitar permanentemente sua própria segurança e a do vizinho (nada de fumo). Trata-se de restaurar a moralidade plugando-a de novo no corpo. O controle sobre o corpo não é um assunto técnico, mas político e moral (Sfez, 1996, p.68)

A repolitização da saúde possibilitou a criação de uma forma de sociabilidade apolítica, que chamaremos de biossociabilidade, para distinguir da biopolítica estatal clássica, constituída por grupos de interesses privados, não mais reunidos segundo padrões tradicionais de agrupamento como classe, estamento, orientação política, mas conforme a critérios de saúde, desempenho físico, doenças específicas, longevidade etc. Nessa cultura da biossociabilidade, criam-se modelos ideais de sujeito baseados na performance física e estabelecem-se novos parâmetros de mérito e reconhecimento, novos valores com base em regras higiênicas e regimes de ocupação de tempo. As ações individuais passam a serem dirigidas com o objetivo de obter melhor forma física, mais longevidade, prolongamento da juventude etc. Na biossociabilidade, todo um vocabulário médico-fisicalista baseado em constantes biológicas, taxas de colesterol, tônus muscular, desempenho corporal, capacidade aeróbica populariza-se e adquire uma conotação 'quase moral' ao fornecer os princípios de avaliação que definem a excelência do indivíduo, antes medida de acordo com o desempenho na esfera pública ou na esfera privada e familiar. Ao mesmo tempo todas as atividades sociais, lúdicas, religiosas, esportivas, sexuais são resignificadas como práticas de saúde (Luz, 2000, 2001). O que alguns autores denominaram de healthism ou bodyism, ${ }^{4}$ e que pode ser traduzido como a

\footnotetext{
${ }^{4}$ A literatura sobre o tópico é imensa. Ver, entre outros: Crawford (1980, 1994); Conrad (1995); Edgley \& Brissett (1990); Petersen (1997); Bunton (1997); Aïach (1998); Faure (1998); Druhle \& Clément (1998); Morris (2000); Greco (1993).
} 
ideologia ou a moralidade da saúde e do corpo perfeito, exprime essa tendência. Healthism é a ideologia, a forma que a medicalização adquire na biossociabilidade.

As práticas ascéticas implicam em processos de subjetivação. As modernas asceses corporais, as bioasceses, reproduzem no foco subjetivo as regras da biossociabilidade, enfatizando-se os procedimentos de cuidados corporais, médicos, higiênicos e estéticos na construção das identidades pessoais, das bioidentidades. Trata-se da formação de um sujeito que se autocontrola, autovigia e autogoverna.

$\mathrm{Na}$ base desse processo está a compreensão do self como um projeto reflexivo. $\mathrm{O}$ autogoverno $e$ a formação de bioidentidades se dão através de toda uma série de recursos reflexivos e de práticas de bioascese (manuais de auto-ajuda, terapias psíquicas e corporais, atividades de fitness e wellness etc). A reflexividade é o processo de taxação contínua de informação $e$ peritagem sobre nós mesmos. Não só o self, mas principalmente o corpo, aparece marcado pela reflexividade (Giddens, 1992; Nettleton, 1997).

$\mathrm{Na}$ atualidade, o discurso do risco é o elemento estruturante básico da biossociabilidade e representa o parâmetro existencial fundamental da vida na modernidade tardia, estruturando o modo pelo qual experts e leigos organizam seus mundos sociais (Castiel, 1999). O corpo e o self são modelados pelo olhar censurador do outro que leva à introjeção da retórica do risco. O resultado é a constituição de um indivíduo responsável que orienta suas escolhas comportamentais e estilos de vida para a procura da saúde e do corpo perfeito e o desvio aos riscos. Ao mesmo tempo podemos observar o crescimento dos comportamentos de risco especialmente na juventude, tais como esportes radicais, sexo sem proteção etc., como resposta à obsessão por comportamentos e estilos de vida sem risco. $\mathrm{O}$ automelhoramento individual autodisciplinado na procura de saúde perfeição corporal tornou-se a forma dos indivíduo exprimirem a sua capacidade de agência $e$ autonomia em conformidade às demandas do mundo competitivo.

A ênfase na autonomia individual está ligada à desmontagem do Estado assistencialista que trata os indivíduos dependentes com desconfiança, como "parasitas sociais": "O tom ácido das atuais discussões das necessidades assistências, direitos e redes de segurança está impregnado de insinuações de parasitismo de um lado, enfrentado pela raiva dos humilhados do outro" (Sennett, 1999, p.170). A valorização da autonomia devolve ao indivíduo a responsabilidade por sua saúde, reduzindo a pressão exercida sobre o sistema público. A condição de autonomia se traduz num melhor estado de saúde e no desenvolvimento de hábitos de vida e escolhas comportamentais saudáveis. No caso da velhice, o modelo biomédico dominante define o envelhecimento exclusivamente em termos de declínio à idade adulta, como um estado patológico, uma doença a ser tratada. Os sinais da idade tornaram-se marcas de aversão e patologia. ${ }^{5}$ Como resultado, os problemas sociais são neutralizados e os idosos são marginalizados em instituições de saúde. Ao mesmo tempo, a velhice é "reconstruída como um estilo de vida mercadológico que conecta os valores mercadológicos da juventude com as
${ }^{5}$ Ver Estes \& Binney (1991); David (1995 p.44-6); Druhle \& Clément $(1998$, p.85) Clarke et al. (2000 p.24); Lupton (1994, p.38-9). 
técnicas de cuidado corporal para mascarar a aparência da idade" (Katz, apud Morris, 2000, p.236). Os idosos da atualidade são apresentados como saudáveis, joviais, engajados, produtivos, autoconfiantes e sexualmente ativos. Como conseqüência, os idosos estão cada vez menos legitimados para recorrer aos sistemas de saúde (David, 1995). O idoso se constitui como um indivíduo responsável e autônomo capaz de cuidar de si. Aparece assim a figura do idoso "bom" e do idoso "mau", este último sem competência para cuidar de si.

Nesse contexto, devemos compreender o surgimento nos últimos anos de grupos de idosos, portadores de deficiências, grupos de 'self care' e movimentos de auto-ajuda, vistos como desafios e resistência à medicalização, e, portanto, encorajados desde a perspectiva da governabilidade neoliberal. Esses grupos retomam o direito dos pacientes participarem no trabalho médico (Pinell, 1998). Eles estimulam, no entanto, a formação de bioidentidades sociais, construídas a partir de uma doença determinada. Como conseqüência, os novos critérios de agrupamento biossociais $e$ biomédicos substituem progressivamente, como vimos, os padrões tradicionais, tais como classe, religião, orientação política.

Nesse contexto, o conceito de deficiência releva o de doença, referindo-se a déficit a serem compensados socialmente e não a doenças a serem tratadas (Rabinow, 1999). Esse conceito, usado oficialmente pela primeira vez na Inglaterra, durante a II Guerra Mundial como uma forma de avaliação da força de trabalho disponível, com o objetivo de incorporar o maior número de pessoas, está na base da biopolítica, cujos grupos se distinguem precisamente pelas deficiências a serem compensadas (deficiência da mulher frente ao homem, do negro frente ao branco, do gay frente ao heterossexual, do portador de deficiências frente ao indivíduo fisicamente normal, dos idosos frente aos jovens etc.). A política se dissolve em políticas particulares que aspiram compensar as deficiências de um grupo biopolítico determinado, cuja uma das conseqüências é o esquecimento de ideais sociais mais abrangentes.

Autores como Robert Castel enfatizam a idéia da dissolução do social como um dos efeitos do olhar biológico, próprio da virada biopolítica nas sociedades ocidentais, nas quais a experiência identitária é calcada na materialidade do biológico e referentes fisicalistas substituem referentes culturais. As aparentes reivindicações (bio)políticas dos grupos constituídos na biossociabilidade são, em muitos casos, uma armadilha, pois, como Graham Burchell (1991, p.145; 1993) reconhece,

é em nome de formas de existência formuladas pelas tecnologias políticas de governo, que nós, como indivíduos e grupos, fazemos reivindicações ao Estado e contra ele. É em nome de nossa existência governada como seres vivos individuais, em nome de nossa saúde, do desenvolvimento de nossas capacidades, de pertencermos a comunidades particulares, de nossa etnicidade, de nosso gênero, de nossas formas de inserção na vida social $e$ econômica, de nossa época, de nosso meio ambiente, dos riscos particulares que podemos enfrentar e assim por diante, que nós igualmente injuriamos e invocamos o poder do Estado.

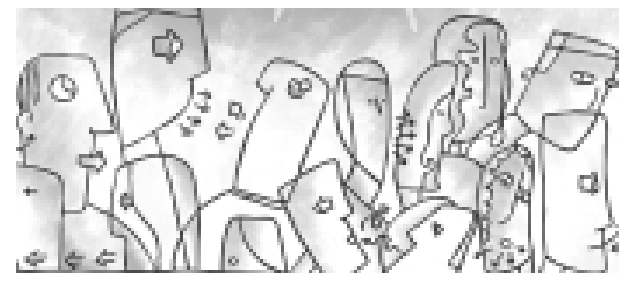




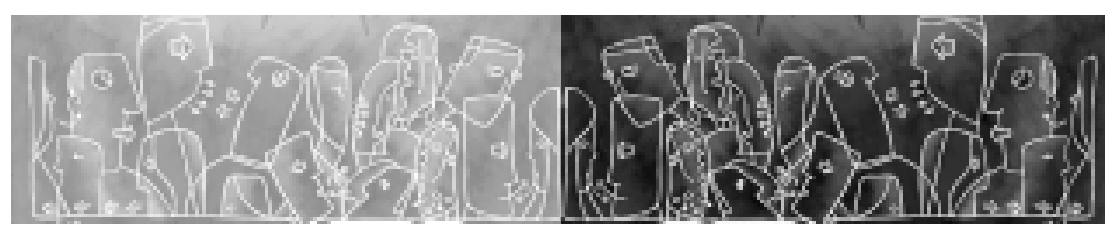

Ou seja, o contexto das reivindicações é sempre o dos grupos biopoliticamente organizados, constituídos precisamente por essas tecnologias de governo. É em nome da autonomia dos idosos que fazemos as reivindicações, a mesma autonomia que se encontra na base das próprias tecnologias governamentais. De fato, ganhamos autonomia, mas a autonomia para nos vigiarmos, a autonomia $e$ a liberdade de nos tornarmos peritos, experts de nós mesmos, da nossa saúde, do nosso corpo. Já dizia Foucault (1976) que a resistência ao biopoder se ampara precisamente naquilo que ele investiu, isto é, na vida mesma, uma vida que se volta contra o sistema que pretende capturá-la. Portanto, a vida constitui o alvo das lutas biopolíticas, mesmo sob a forma de lutas pelo direito à vida, à saúde, ao corpo, à higiene, ao bemestar e à satisfação das necessidades. A biopolítica precisa da resistência ao dispositivo biopolítico para poder se desenvolver.

Por outro lado, o surgimento de grupos de idosos e de portadores de deficiências é correlato à imposição de uma ideologia que menospreza e estigmatiza a velhice, a doença $e$ a deformação física. A organização desses grupos constitui uma reação, uma tentativa de resistir a essa imposição ideológica. Às vezes, esses grupos de idosos se constituem para realizar trabalhos sociais, recuperar e propor práticas de solidariedade e formas de sociabilidade alternativas e não só para viver os ideais de longevidade, (aparente) juventude, proezas sexuais, o que seria se adaptar a essa ideologia da saúde, da vitalidade, da longevidade (Luz, 2000, 2001).

Depois do dito até agora, poderíamos pensar que as questões 'defendidas' pelos grupos biopolíticos, tais como a situação de mulheres, negros, gays, emigrantes, a proteção do meio ambiente etc., são irrelevantes na agenda filosófico-política helleriana. Ora, a crítica de Agnes Heller se dirige não contra os assuntos em si; eles são, evidentemente, importantes, mas contra a maneira de serem abordadas na biopolítica de raça, gênero, saúde. Pois, ao serem abordados biopoliticamente, são imediatamente despolitizados, devido à mencionada "tendência a uniformizar o indivíduo, sua intolerância respeito ao insólito e ao excêntrico, sua inclinação a uma ditadura da maioria, sua predileção por modelar uma 'opinião correta' coletiva e coisas semelhantes" (Heller E Feher, 1995, 119-20). É a partir da crítica ao pensamento arendtiano e seu desprezo pela questão social que encontramos um fundamento para um tratamento adequado dos conflitos de raça, gênero, saúde etc. Arendt acreditava que a politização de assuntos sociais levou ao declínio da política, como testemunharia o fracasso da Revolução Francesa e o sucesso da Revolução Americana, já que na segunda a questão social não foi colocada (Arendt, 1988). Para Heller, pelo contrário, é a politização da questão social o que salvaria de tratar as mesmas questões biopoliticamente. O exemplo dos Estados Unidos é paradigmático nesse sentido, pois precisamente a ausência histórica de politização dos assuntos sociais possibilitou que "entretanto os movimentos biopolíticos de América tenham assumido o comando ideológico" (Heller, 1995, s/p). Haveria assim duas maneiras antagônicas de tratar temas que dizem respeito à raça, 
gênero, saúde e meio ambiente: biopoliticamente ou como politização de assuntos sociais. Só a segunda seria stricto sensu política. A diferença estaria no conceito do político que está operando em cada caso; na biopolítica estaríamos tratando com o conceito do político de Carl Schmitt (1992), entendido como a discriminação entre amigo e inimigo ${ }^{6}$. No caso da politização de questões sociais, o conceito do político correspondente é a concretização da liberdade no espaço público, segundo o qual qualquer assunto torna-se político se é decido, discutido, debatido no espaço público, deixando de sê-lo ao abandonar a esfera pública (Heller, 1990):

Se um grupo determinado só aceita sua auto-apresentação e exclui as apresentações dos outros, para si mesmo, no entanto, exige o direito de apresentar a seus inimigos, então isso é biopolítica. Se a opinião pública exige uma variedade de apresentações e representações recíprocas, estamos lidando com um assunto social. Se o indivíduo só conta como representante de seu grupo, então isso é biopolítica. Se se trata da opinião do indivíduo, é e fica sendo uma questão social. Se os movimentos defendem principalmente sanções e restrições legais, é biopolítica. Se a Societas da Paideia tem a primazia e favorece a educação, o respeito mútuo, a polidez, a franqueza, então se trata de uma questão social politizada. (Heller, 1995, s/p)

\section{Referências}

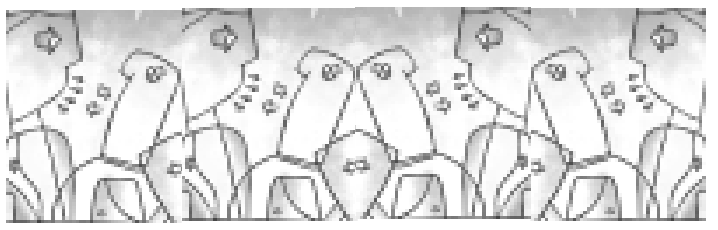

AGAMBEN, G. Homo sacer: el poder soberano y la nuda vida. Valencia: Pre-Textos, 1998.

AÏACH, P. Les voies de la médicalisation. In: AÏACH, P.; DELANOË, D. (Orgs.) L’ere de la médicalisation: ecce homo sanitas. Paris: Economica, 1998. p.15-36.

ARENDT, H. Da Revolução. São Paulo: Editora Ática/Editora da UnB, 1988.

ARENDT, H. A condição humana. São Paulo: Forense Universitária, 1995.

ARENDT, H. As origens do totalitarismo. São Paulo: Companhia das Letras, 1997.

BUNTON, R. Popular health, advanced liberalism and good housekeeping. In: PETERSEN, A.; BUNTON, ROBIN (Orgs.) Foucault, Health and Medicine. London: Routledge, 1997. p.223-48.

BURCHELL, G. Peculiar interests: civil society and governing 'The System of Natural Liberty'. In: BURCHELL, G.; GORDON, C.; MILLER, P. (Orgs.) The Foucault effect: studies in Governmentality. Hemel Hempstead: Harvester Wheatsheaf, 1991. p.119-50.

BURCHELL, G. Liberal government and techniques of the self. Economy Soc., v.22, n.3, p.267-82, 1993.

CASTIEL, L. D. A medida do possível... saúde, risco e tecnobiociências. Rio de Janeiro: Contracapa, 1999.

CLARKE, A. E.; FISHMAN, J.; FOSKET, J. R.; MAMO, L.; SHIM, J. K. Technosciences et nouvelle biomédicalisation: racines occidentales, rhizomes mondiaux. Sciences Sociales et Santé, v.18, n.2, p.11-40, 2000.

CONRAD, P. Médicalisation et contrôle social. In: BOUCHARD, L.; COHEN, D. (Orgs.) Médicalisation

${ }^{6}$ Segundo Schmitt (1992, p.51, 55-6), “a distinção especificamente política a que podem reportar-se as ações e os motivos políticos é a discriminação entre amigo e inimigo"; "O antagonismo político é a mais intensae extrema contraposição e qualquer antagonismo concreto é tanto mais político, quanto mais se aproximar do ponto extremo, do agrupamento amigoinimigo". 
et contrôle social: Les cahiers scientifiques de l'Acfas. Quebec: 84, 1995. p.9-34.

CRAWFORD, R. Healthism and the medicalization of everyday life. Intern. J. Health Services, v.10, n.3, p.365-88, 1980.

CRAWFORD, R. The boundaries of the self and the unhealthy other: reflections on health, culture and aids. Soc. Scienc. Med., v.38, n.10, p.1347-65, 1994.

DAVID, H. 1995 L'insoutenable lourdeur de l'autonomie pour les personnes âgées. In: BOUCHARD, L.; COHEN, D. (Orgs.) Médicalisation et contrôle social: les cahiers scientifiques de l'Acfas. Quebec: 84, 1995. p.43-66.

DELEUZE, G. Foucault. Paris: Gallimard, 1986.

DRUHLE, M.; CLÉMENT, S. Enjeux et formes de la médicalisation: d'une approche globale au cas de la gérontologie. In: AÏACH, P.; DELANOË, D. (Orgs.) L’ere de la médicalisation: ecce homo sanitas. Paris: Economica, 1998. p.69-96.

EDGLEY, C.; BRISSETT, D. Health nazis and the cult of the perfect body: some polemical observations. Symbolic Interaction, v.13, n.2, p.257-79, 1990.

ESTES, C. L.; BINNEY, E. A. The biomedicalization of aging: dangers and dilemmas. In: MINKLER, M.; ESTES, C. L. (Orgs.) Critical perspectives on aging. New York: Baywood Publishing Company, 1991. p.117-34.

FAURE, O. La médicalisation vue par les historiens. In AÏACH, P.; DELANOË, D. (Orgs.) L’ere de la médicalisation: ecce homo sanitas. Paris: Economica, 1998. p.53-68.

FOUCAULT, M. La volonté de savoir. Paris: Gallimard, 1976.

FOUCAULT, M. Em defesa da sociedade. São Paulo: Martins Fontes, 1999a.

FOUCAULT, M. Les anormaux: cours au collège de France, 1974-1975. Paris: Hautes Études, 1999b.

GIDDENS, A. A transformação da intimidade. São Paulo: Ed. Unesp, 1992.

GRECO, M. Psychosomatic subjects and the 'duty to be well': personal agency within medical rationality. Economy and Society, v.22, n.3, p.357-72, 1993.

HELLER, A. The concept of the political revisited: can modernity survive? Los Angeles: University of California Press, 1990.

HELLER, A. Achtung Europa!, Über die Biologisierung des Politischen. Disponível em <www.hannaharendt.de/verein/publikationen_heller.html>. Acesso em 05 mai. 2003.

HELLER, A.; FEHER, F. Biopolítica: la modernidad y la liberación del cuerpo. Barcelona: Península, 1995.

LUPTON, D. Medicine as culture: illness, disease and the body in western societies. London: Sage, 1994.

LUZ, M. La salud en forma y las formas de la salud: superando paradigmas y racionalidades. In: BRICEÑO-LEON, R.C.; MINAYO, C. E.; COMBRA, C. (Orgs.) Salud y equidad: una mirada desde las ciencias sociales. Rio de Janeiro: Fiocruz, 2000. p.181-200.

LUZ, M. O vazio nas relações sociais na cultura atual. In: DA POIAN, C. (Org.) Formas do vazio: desafios ao sujeito contemporâneo. São Paulo: Via Lettera, 2001. p.49-66.

MORRIS, D. B. IIIness and culture in the postmodern age. Berkeley and Los Angeles: University of California Press, 2000.

NETTLETON, S. Governing the risky self: how to become healthy, wealthy and wise. In: PETERSEN, A.; BUNTON, R. (Orgs.) Foucault, Health and Medicine. London: Routledge, 1997. p.207-22. 
ORTEGA, F.

ORTEGA, F. Amizade e estética da existência em Foucault. Rio de Janeiro: Graal, 1999.

ORTEGA, F. Para uma política da amizade: Arendt, Derrida, Foucault. Rio de Janeiro: Relume Dumará, 2000.

ORTEGA, F. Genealogias da amizade. São Paulo: lluminuras, 2002.

PETERSEN, A. Risk, governance and the new public health. In: PETERSEN, A.; BUNTON, R. (Orgs.)

Foucault, Health and Medicine. London: Routledge, 1997. p.189-206.

PINELL, P. Médicalisation et procès de civilisation. In: AÏACH, P.; DELANOË, D. (Orgs.) L’”ere de la médicalisation: ecce homo sanitas. Paris: Economica, 1998. p.37-51.

RABINOW, P. Artificialidade e iluminismo: da sociobiologia à biossociabilidade. Antropologia da razão. Rio de Janeiro: Relume Dumará, 1999.

SCHMITT, C. O conceito do político. Petrópolis: Vozes, 1992.

SENNETT, R. A corrosão do caráter. Rio de Janeiro: Record, 1999.

SFEZ, L. A saúde perfeita: crítica de uma nova utopia. Loyola: São Paulo, 1996.

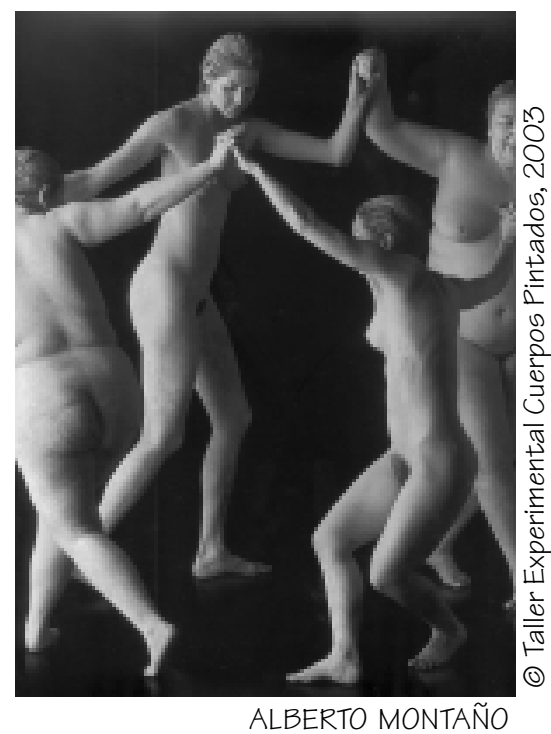

ORTEGA, F. Biopolíticas de la salud: reflexiones a partir de Michel Foucault, Agnes Heller y Hannah Arendt, Interface - Comunic., Saúde, Educ., v.8, n.14, p.9-20, set.2003-fev.2004.

El objetivo de este artículo es ofrecer herramientas conceptuales que puedan ayudar en la reflexión acerca de la cuestión de las biopolíticas de la salud a partir de la obra de Michel Foucault, Agnes Heller y Hannah Arendt. Para Foucault, desde el siglo XVIII, la vida biológica y la salud de la nación se tornaron puntos fundamentales de un poder sobre la vida que enfatizaba especialmente las nociones de sexualidad, raza y degenerescencia, cuyo objetivo era la optimización de la calidad biológica de las poblaciones. Para Arendt, ese movimiento de politización de la vida es profundamente antipolítico. La vida pasa a ocupar el vacío dejado por la descomposición del ámbito público. En el caso de Agnes Heller, el antipolitismo del discurso biopolítico se manifiesta en la búsqueda constante de legitimación casi científica. El pensamiento de raza, género, salud es un pensamiento científico imitado que substituye la opinión por la verdad. Si la política es el campo do confrontación de las opiniones, del diálogo, de la iniciativa, de lo nuevo, de la espontaneidad y de la acción en libertad, el pensamiento biopolítico legitimado científicamente es el espacio de la verdad, de la certeza, de la necesidad, del determinismo y de la causalidad, en el cual el diálogo es substituido por una política da autoclausura, de amigos y enemigos, y la pluralidad de opiniones es reducida a una única opinión políticamente correcta.

PALABRAS CLAVE: Biopolítica; salud; Michel Foucault; Agnes Heller; Hannah Arendt. 